\title{
A stereodivergent asymmetric approach to difluorinated aldonic acids $\dagger$
}

\author{
Christophe Audouard, ${ }^{a}$ Igor Barsukov, ${ }^{b}$ John Fawcett, ${ }^{a}$ Gerry A. Griffith, ${ }^{a}$ Jonathan M. Percy, ${ }^{* a}$ \\ Stéphane Pintat ${ }^{c}$ and Clive A. Smith ${ }^{d}$ \\ a Department of Chemistry, University of Leicester, University Road, Leicester, UK LE1 7RH. \\ E-mail: jmp29@le.ac.uk; Fax: +44 116252 3789; Tel: +44 1162522140 \\ ${ }^{b}$ Biological NMR Centre, University of Leicester, PO Box 138, University Road, Leicester, UK LE1 9HN \\ ${ }^{c}$ Evotech OAI, 151 Milton Park, Abingdon, Oxon, UK OX14 4SD \\ ${ }^{d}$ GlaxoSmithKline Pharmaceuticals, New Frontiers Science Park, Third Avenue, Harlow, UK CM19 5AW
}

Received (in Cambridge, UK) 6th April 2004, Accepted 28th April 2004
First published as an Advance Article on the web 27th May 2004

A (bromodifluoromethyl)alkyne has been deployed in a stereoselective route to difluorinated aldonic acid analogues, in which a Sharpless asymmetric dihydroxylation reaction and diastereoisomer separation set the stage for phenyl group oxidation. $\dagger$

Though there are hundreds of fluorinated sugars in the chemical literature, some of which have extremely useful properties, few have been made by the concise processing of readily-available fluorinated starting materials or building blocks. Fluorination approaches, in which an hydroxy group, or ketone carbonyl is exposed selectively to a fluorinating agent such as DAST or DeoxoFluor are much more common. ${ }^{1}$ However, such methods lack the potential for stereodivergent synthesis; by this we mean that most syntheses start from an available sugar and deliver an unique product. Building block chemistry has the potential to generate families of related sugar analogues in high enantiomeric enrichment if suitable fluorinated materials can be transformed using the modern methods of asymmetric synthesis but aside from the asymmetric reductions of perfluoroalkylketones and related species, there are few useful methods. ${ }^{2}$

Recently, we described the first racemic syntheses of 4-deoxy4,4-difluorosugars from 1-bromo-1,1-difluoropropene and a protected glycolaldehyde derivative. ${ }^{3}$ The target glycosides appear to be of growing interest with recent publications by $\mathrm{Liu}^{4}$ and Mobashery. 5 However, our syntheses were racemic, with no obvious potential for the control of absolute configuration. Retrosynthetic analysis (Scheme 1), exploiting the well-known synthetic equivalence of the phenyl group for a carboxyl function, ${ }^{6}$ suggested that alkynyl diol 1 could be a strategic precursor to a family of 4-deoxy-4,4-difluorosugars. Key steps would include the addition of the alkyne to a glycolaldehyde, stereoselective reduction to the $E$-alkene, Sharpless AD followed by diastereoisomer separation and oxidative cleavage of the phenyl group. Very few Sharpless AD reactions of fluorinated alkene substrates have been reported. ${ }^{7}$ FMO influences upon the reaction are complex ${ }^{8}$ so the

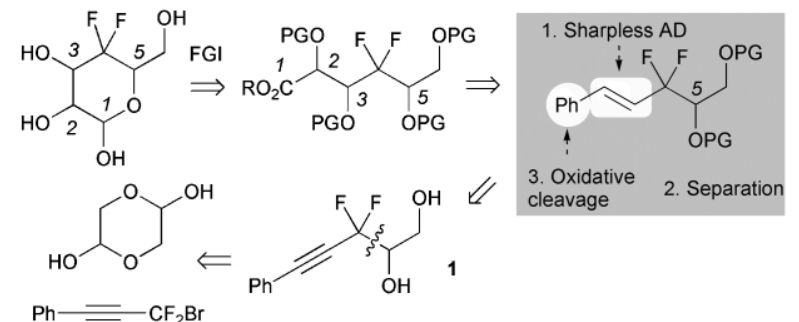

Scheme 1 Retrosynthetic analysis and identification of pivotal intermediate

$\dagger$ Electronic supplementary information (ESI) available: preparation of $\mathbf{1}$ and 2a, NMR and electrospray for $\mathbf{1 4}$ (deuterium exchanged), chiral HPLC traces for $\mathbf{7 a}$ and $\mathbf{7 b}$, optical rotations for $\mathbf{7 a - 8 b}$. See http://www.rsc.org/ suppdata/cc/b4/b405067c/ effect of the $\mathrm{CF}_{2}$ centre was hard to predict, though we assume that the presence of a phenyl group will facilitate the oxidation, and that our substrates will follow the usual behaviour of $\beta$-substituted styrenes.

Kobayashi ${ }^{9}$ developed propargylation reactions (Scheme 2) with 2a-2c for a synthesis of the sugar portion of Gemcitabine. ${ }^{10}$ However, alkyne building blocks 2a-2c could only be synthesised in moderate yield. Hammond revisited this area profitably, developing an efficient synthesis of TIPS acetylene 2d, ${ }^{11 a}$ and showing that it reacts under zinc $^{11 \mathrm{~b}}$ and indium ${ }^{11 \mathrm{c}}$ mediated conditions and can be used to prepare a range of functionally complex molecules ${ }^{11 d}$ containing a $\mathrm{CF}_{2}$ group. Alkyne 2a was prepared in modest yield by Wakselman and co-workers ${ }^{12}$ from lithium phenylacetylide and dibromodifluoromethane; we found that pre-cooling the dibromodifluoromethane electrophile (to -78 ${ }^{\circ} \mathrm{C}$ ) before addition to the lithioalkyne allowed 2a to be isolated in excellent $(85 \%)$ yield after distillation on a 0.25 mole scale. Small scale ( $<5$ mmole) additions of $\mathbf{2 a}$ to commercial glycolaldehyde proceeded smoothly under the Kobayashi conditions to afford $\mathbf{1}$, whereas the Hammond conditions delivered only diyne 4. On a 5 mmole scale, Kobayashi's conditions resulted in the formation of $\mathbf{1}$ in poor yield. A 24 reaction screen revealed two effective sets of conditions based upon the common use of zinc metal. The highest yielding reactions occurred with either $5 \% \mathrm{Hg}(\mathrm{OAc})_{2} / \mathrm{NaI} / \mathrm{Zn}$ in THF or $5 \% \mathrm{Hg}\left(\mathrm{OCOCF}_{3}\right)_{2} / \mathrm{Zn}$ in DMF. The former regime delivered a reliable $68-70 \%$ yield of 1 at scales between 1 and 89 mmole. We were unable to obtain any product at all under aqueous conditions.

The alkynyl group was reduced stereoselectively with Red-Al (72\%), ${ }^{13}$ and protection of the racemic diol as the acetonide 5 was achieved smoothly (95\%). Sharpless AD occurred slowly unless $N$ methane sulfonamide was present in the reaction. Pleasingly, the reactions reached completion after 3 days and were high yielding ( $83 \%$ for $\mathrm{AD}$ MIX- $\vee, 91 \%$ for $\mathrm{AD} \mathrm{MIX}^{-}{ }^{-}$). No advantage was gained by constant $\mathrm{pH}$ adjustment. ${ }^{14}$

The two pairs of inseparable diastereoisomeric diols $6 \mathbf{a}$ and $\mathbf{6 b}$ were protected as the bis-acetonides (which were separated effectively by conventional flash column chromatography to afford 4 separate bis-acetonides 7a-8b (43, 41, 46 and $48 \%$ isolated yields in that order). The 1,3-anti (7a and 7b) and 1,3-syn (8a and $\mathbf{8 b}$ ) diols have very different ${ }^{19} \mathrm{~F}$ NMR spectra as described by Ishihara, ${ }^{15}$ and we were able to obtain a crystal structure from $7 \mathbf{b}$ to confirm the assignment of relative configuration. $\$ \S$

Samples of 7a and $\mathbf{7 b}$ were mixed and eluted through a Chiralcel OJ column; a good separation was obtained and the individual components were enantiomerically-enriched to a level of $95 \%$ from

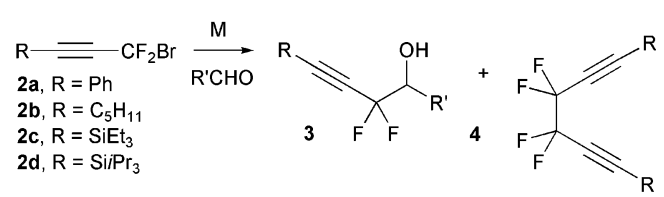

Scheme 2 Developing an addition methodology (see text). 
AD-mix $\beta$ and $99.5 \%$ from AD-mix $\alpha$. Unfortunately, we were not able to separate $8 \mathbf{a}$ and $\mathbf{8 b}$ using any column available to us, though the similar measured rotations show clearly that these products are not racemic and that the ee's are similar to those obtained for the separated isomers.

Oxidative cleavage of the phenyl ring has been reported in the presence of an acetonide protecting group. ${ }^{16} \mathrm{We}$ attempted the oxidation, believing that the presence of the $\mathrm{CF}_{2}$ centre would make acetal cleavage more difficult by suppressing the pre-equilibrium protonation at the beginning of the hydrolysis pathway. However, a complex mixture of products was obtained from which we identified desired product $\mathbf{9}$, along with $\mathbf{1 0}$ and $\mathbf{1 1}$. Given the measured $\mathrm{pH}$ of 2.9 at the start of the reaction, acetal hydrolysis is not surprising, so the literature observation is remarkable.

Methanolysis of the bis-acetonide 7a and per-acetylation to 12II set the stage for successful oxidative cleavage and $\mathbf{1 3}$ was isolated after work-up with TMS diazomethane ( $42 \%$ over 2 steps). No epimerisation was detected by GC or ${ }^{19} \mathrm{~F}$ NMR. Exposure to catalytic $\mathrm{K}_{2} \mathrm{CO}_{3}$ in methanol delivered a product with the mass (revealed by ES-MS) and NMR spectra of aldonic acid 14. || HMBC analysis was used to confirm the acyclic structure.

We have described the first total synthesis of a difluorosuga which gives rise to highly enantiomerically-enriched products. The method is direct and stereodivergent, assuming the other three diastereoisomers can be treated in the same way and breaks new ground in the stereoselective synthesis of difluoroanalogues of natural products.

We wish to thank the EPSRC (GR/K84882) and the Universities of Leicester and Birmingham and GSK (CASE studentship to SP)

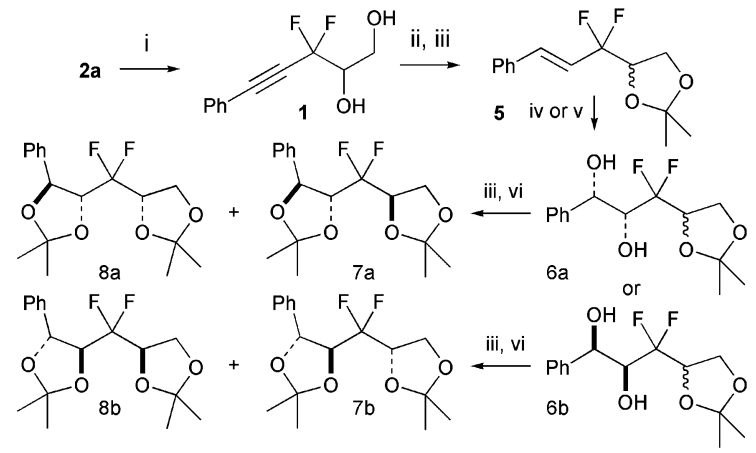

Scheme 3 Stereoselective reduction and dihydroxylation reactions. Reagents and conditions. i, $5 \% \mathrm{Hg}(\mathrm{OAc})_{2} / \mathrm{NaI} / \mathrm{Zn}$, THF; ii, Red-Al, PhMe, rt; iii, acetone, TsOH, $\mathrm{CuSO}_{4}$; iv, $\mathrm{MeSO}_{2} \mathrm{NH}_{2}$ and $\mathrm{AD}$ mix- $\beta$ for $7 \mathbf{a}$; v, $\mathrm{MeSO}_{2} \mathrm{NH}_{2}$ and AD mix- $\alpha$ for $\mathbf{7 b}$; vi, flash column chromatography.

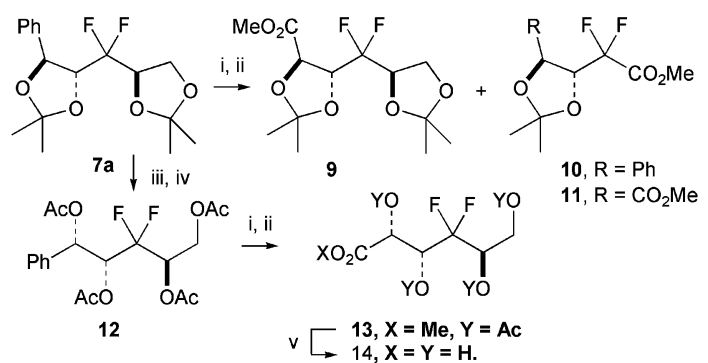

Scheme 4 Elaboration of the protected $\mathrm{AD}$ products. i, $\mathrm{RuCl}_{3}, \mathrm{NaIO}_{4}$, $\mathrm{MeCN} / \mathrm{CCl}_{4} / \mathrm{H}_{2} \mathrm{O}$, rt; ii, TMSCHN ${ }_{2}$, THF; iii, Amberlyst- $15, \mathrm{MeOH}, 40{ }^{\circ} \mathrm{C}$, 24 hours, $75 \%$; iv, $\mathrm{Ac}_{2} \mathrm{O}$, pyridine, rt, 24 hours, $96 \%$; v, $10 \% \mathrm{~K}_{2} \mathrm{CO}_{3}$, $\mathrm{MeOH}, 0{ }^{\circ} \mathrm{C}$. and the EPSRC (GR/R96835, fellowship to CA). We also wish to thank Mr M Lee for assistance with the chiral HPLC.

\section{Notes and references}

$\ddagger$ Crystallographic data for $7 \mathbf{b}: \mathrm{C}_{17} \mathrm{H}_{22} \mathrm{~F}_{2} \mathrm{O}_{4}$, crystal size $0.33 \times 0.21 \times 0.14$ $\mathrm{mm}, M=328.15$, orthorhombic, $a=9.7774(6), b=11.6322(7), c=$ 14.7974(9) $\AA, \alpha=90, \beta=90, \gamma=90^{\circ}, U=1682.95(18) \AA^{3}, T=150(2)$ $\mathrm{K}$, space group $P 2(1) 2(1) 2(1), Z=4, \mu(\mathrm{Mo}-\mathrm{K} \alpha)=0.105 \mathrm{~mm}^{-1}, 11573$ reflections measured, 2966 unique $\left(R_{\text {int }}=0.0260\right)$ which were used in all calculations). Final $R$ indices $\left[F^{2}>2 \sigma\left(F^{2}\right) R 1=0.0298, \mathrm{w} R 2=0.0728\right.$; $\mathrm{R}$ indices (all data) $R 1=0.0315, \mathrm{w} R 2=0.0735$.

§ CCDC 235709 and 235710. See http://www.rsc.org/suppdata/cc/b4/ b405067c/ for crystallographic data in .cif or other electronic format.

II A crystal structure confirmed the stereochemistry was unchanged. Crystallographic data for $12: \mathrm{C}_{19} \mathrm{H}_{22} \mathrm{~F}_{2} \mathrm{O}_{8}$, crystal size $0.36 \times 0.19 \times 0.06$ $\mathrm{mm}, M=416.37$, monoclinic, $a=11.5206(15), b=5.7277(7), c=$ 15.792(2) $\AA, \alpha=90, \beta=107.137(2), \gamma=90^{\circ}, U=995.8(2) \AA^{3}, T=$ $150(2) \mathrm{K}$, space group $P 2(1), Z=2, \mu(\mathrm{Mo}-\mathrm{K} \alpha)=0.120 \mathrm{~mm}^{-1}, 7293$ reflections measured, 3466 unique $\left(R_{\text {int }}=0.0257\right)$ which were used in all calculations). Final $R$ indices $\left[F^{2}>2 \sigma\left(F^{2}\right) R 1=0.0413\right.$, w $R 2=0.0877$; $\mathrm{R}$ indices (all data) $R 1=0.0484, \mathrm{w} R 2=0.0910$.

$\|$ Data for 14. Semi solid, $\delta_{\mathrm{H}}\left(\mathrm{D}_{2} \mathrm{O}, 500 \mathrm{MHz}\right) 4.35-4.25$ (2H, m, H-2, H-3), 4.10-4.01 $\left(1 \mathrm{H}, \mathrm{m}\right.$ [app. d, $\left.\left.{ }^{3} J_{\mathrm{H}-\mathrm{F}} 20.7\right], \mathrm{H}-5\right), 3.85\left(1 \mathrm{H}\right.$, broad d, , $\mathrm{H}_{6 \mathrm{a}},{ }^{2} J$ $14.1), 3.68\left(1 \mathrm{H}, \mathrm{dd}, \mathrm{H}_{6 \mathrm{~b}}, J 8.4,{ }^{2} J 14.1\right) ; \delta_{\mathrm{C}}\left(\mathrm{D}_{2} \mathrm{O}, 125 \mathrm{MHz}\right): 180.6(\mathrm{C}-1)$, $124.6\left(\mathrm{t},{ }^{1} J_{\mathrm{C}-\mathrm{F}} 212.5, \mathrm{C}-4\right), 72.7(\mathrm{C}-2), 72.5\left(\mathrm{dd},{ }^{2} J_{\mathrm{C}-\mathrm{F}} 19.1,14.4, \mathrm{C}-3\right), 72.1$ $\left(\mathrm{dd},{ }^{2} J_{\mathrm{C}-\mathrm{F}} 33.6,28.1, \mathrm{C}-5\right), 62.8(\mathrm{C}-6) ; \delta_{\mathrm{F}}\left(\mathrm{D}_{2} \mathrm{O}, 282 \mathrm{MHz}\right)-121.7(1 \mathrm{~F}, \mathrm{dd}$, $\left.{ }^{2} J_{\mathrm{F}-\mathrm{F}} 260.0,{ }^{3} J_{\mathrm{H}-\mathrm{F}} 19.4\right),-123.3\left(1 \mathrm{~F}, \mathrm{dd},{ }^{2} J_{\mathrm{F}-\mathrm{F}} 260.0,{ }^{3} J_{\mathrm{H}-\mathrm{F}} 20.7\right) ; \mathrm{m} / \mathrm{z}$ $\left(\mathrm{ES}^{-}\right) 215\left(\mathrm{M}-\mathrm{H}^{+}, 100 \%\right)$

1 K. Dax, M. Albert, J. Ortner and B. J. Paul, Carbohydr. Res., 2000, 327, 47; R. P. Singh and J. M. Shreeve, Synthesis, 2002, 2561.

2 See for example: P. V. Ramachandran, B. Q. Gong, A. V. Teodorovic and H. C. Brown, Tetrahedron: Asymmetry, 1994, 5, 1061; H. Abe, H. Amii and K. Uneyama, Org. Lett., 2001, 3, 313.

3 C. Audouard, J. Fawcett, G. A. Griffith, J. M. Percy, S. Pintat and C. A. Smith, Org. Biomol. Chem., 2004, 2, 528.

4 H. W. Chen, Z. B. Zhao, T. M. Hallis, Z. H. Guo and H. W. Liu, Angew. Chem. Int. Ed., 2001, 40, 607.

5 C. Kim, J. Haddad, S. B. Vakulenko, S. O. Meroueh, Y. Wu, H. Yan and S. Mobashery, Biochemistry, 2004, 43, 2373.

6 P. H. J. Carlsen, T. Katsuki, V. S. Martin and K. B. Sharpless, J. Org. Chem., 1981, 46, 3936.For applications of this methodology, see F Matsuura, Y. Hamada and T. Shiori, Tetrahedron, 1993, 49, 8211; J. Clayden, F. E. Knowles and C. J. Menet, Tetrahedron Lett., 2003, 44, 3397; T. S. Cooper, P. Laurent, C. J. Moody and A. K. Takle, Org. Biomol. Chem., 2004, 2, 265.For a review, see L. N. Mander and C. M. Williams, Tetrahedron, 2003, 59, 1105

7 K. P. M. Vanhessche and K. B. Sharpless, Chem. Eur. J., 1997, 3, 517; F. A. Davis, P. V. N. Kasu, G. Sundarababu and H. Qi, J. Org. Chem., 1997, 62, 7546

8 D. W. Nelson, A. Gypser, P. T. Ho, H. C. Kolb, T. Kondo, H. L. Kwong, D. V. McGrath, A. E. Rubin, P. O. Norrby, K. P. Gable and K. B. Sharpless, J. Am. Chem. Soc., 1997, 119, 1840.

9 Y. Hanzawa, K. Inazawa, A. Kon, H. Aoki and Y. Kobayashi, Tetrahedron Lett., 1987, 28, 659.

10 T. S. Chou, P. C. Heath, L. E. Patterson, L. M. Poteet, R. E. Lakin and A. H. Hunt, Synthesis, 1992, 565.

11 (a) Z. G. Wang and G. B. Hammond, Chem. Commun., 1999, 2545; (b) Z. G. Wang and G. B. Hammond, J. Org. Chem., 2000, 65, 6547; (c) Z G. Wang and G. B. Hammond, Tetrahedron Lett., 2000, 41, 2339; (d) Q L. Shen and G. B. Hammond, J. Am. Chem. Soc., 2002, 124, 6534

12 I. Rico, D. Cantacuzene and C. Wakselman, J. Chem. Soc., Perkin Trans. 1, 1982, 1063.

13 T. Yamazaki, K. Mizutani and T. Kitazume, J. Org. Chem., 1995, 60, 6046.

14 G. M. Mehltretter, C. Dobler, U. Sundermeier and M. Beller, Tetrahedron Lett., 2000, 41, 8083.

15 M. Kuroboshi and T. Ishihara, Bull. Chem. Soc. Jpn., 1990, 63, 1185.

16 T. Yokomatsu, Y. Yoshida, K. Suemune, T. Yamagishi and S. Shibuya, Tetrahedron: Asymmetry, 1995, 6, 365. 